\title{
Thermal Runaway of Dried Sewage Sludge Granules in Storage Tanks
}

\author{
Martine S. Poffet ${ }^{\mathrm{a}}$, Kurt Käser ${ }^{\mathrm{b}}$, and Titus A. Jenny ${ }^{\star a}$
}

\begin{abstract}
Elimination of the sewage sludge from urban wastewater occurs exclusively by incineration in Switzerland, because recycling as fertilizer in agriculture has been banned since October 2006. Two options exist for elimination, either thermal elimination of a thickened sludge in a household waste incineration plant, or drying of the thickened sludge to yield a granular material fit for storage and transport. The high organic content of this material makes it a valuable alternative fuel for the cement industry. This elimination route is hampered, however, by the tendency of this material to self-heating and occasional thermal runaway resulting in fire. This research project deals with the investigation of the characteristics of these dried sewage sludge granules and the possible reasons for the observed self-heating phenomenon. It was found that a cascade of reactions and a series of circumstances are responsible for the thermal runaway, where each of them isolated would not lead to an event. Mainly responsible for triggering the initial temperature raise is the oxidation of $\mathrm{Fe}(I)$ compounds, added to the wastewater as $\mathrm{FeClSO}_{4}$ for phosphate precipitation, and present in this lower oxidation state due to the reducing conditions in the digesters. Sulfate reduction to sulfide by sulfate-reducing bacteria (SRB) presents an additional source of latent heat in the final product once brought in contact with air as demonstrated by the observed formation of the high temperature allotrope $\gamma$-sulfur.
\end{abstract}

Keywords: Sewage sludge granules - Waste disposal

\section{Introduction}

Urban wastewater consists of impure water released by residential, institutional, commercial and industrial facilities. ${ }^{[1]}$ Such water carries all sorts of undesirable compounds such as toxic and polluting substances and pathogenic organisms, but also valuable substances like plant nutrients.

${ }^{*}$ Correspondence: Prof. Dr. T. A. Jennya

Tel.: +4126300 8778

Fax: + 41263009738

E-mail: titus.jenny@unifr.ch

aDepartment of Chemistry

University of Fribourg

Chemin du Musée 9

$\mathrm{CH}-1700$ Fribourg

bDepartment of Industrial Technologies

College of Engineering and Architecture of Fribourg

Bd de Pérolles 80 - CP 32

$\mathrm{CH}-1705$ Fribourg
To remove the harmful compounds, the wastewater is therefore collected through the sewer and directed to a sewage treatment plant (STP) where it is purified by several physical, chemical and biological processes. ${ }^{[2]}$ Resulting from this complex treatment, on the one hand, purified water is released into the effluents and on the other hand sewage sludge is retained as waste. At first sewage sludge is a liquid suspension with $\sim 4 \%$ dry solids (DS) content, which is then centrifuged to obtain dewatered sludge ( $\sim 35 \%$ DS), or even dried further resulting finally in dried sewage granules $(\sim 92 \%$ DS, size typically up to $3 \mathrm{~mm}$ ).

Until recently the sewage sludge was mainly used as fertilizer in agriculture thanks to the nutritive substances like phosphates and nitrogen-containing compounds. However, the recycling of such waste also causes negative effects on the ecosystem $^{[3]}$ due to the presence of heavy metal ions, ${ }^{[4]}$ persistent organic pollutants ${ }^{[5]}$ or even pharmaceuticals ${ }^{[6,7]}$ in the final sewage product. For this reason, the Swiss Federal Government banned the use of sludge as a fertilizer in order to prevent any risk of irreversible damage to the soil and hence to the population. Fertilization with sewage sludge has been restricted stepwise since May 2003 and was universally banned in October 2006
As a consequence, a new elimination route had to be found for this significant waste product: in 2002, Switzerland produced 200 '000 tonnes DS of sewage sludge and this amount has changed little since. Its high organic content, $\sim 50 \%$ DS, allows the incineration of this sewage waste and therefore the thermal conversion to ash presented a suitable option. Therefore, all the sewage waste produced in Switzerland needs to be incinerated respecting environmentally friendly norms. Moreover energy production from combustive waste elimination is a doubly beneficial strategy, because burning waste is considered $\mathrm{CO}_{2}$-neutral in accordance with Swiss policy on the implementation of the Kyoto protocol. ${ }^{[8]}$ Sewage sludge is therefore considered as a 'green' fuel in contrast to conventional fossil energy sources.

In 200240 '000 tonnes DS of sewage sludge ( $20 \%$ of the Swiss production) were already incinerated by the cement industry, ${ }^{[9]}$ because this process binds most of the ashes in the produced clinker. The dried sewage granules are transported to the cement plants by road, where they are transferred with compressed air from the truck into large storage silos. From there the sewage material is transported through pipes to the furnace when needed as auxiliary fuel for the cement production. 


\section{Self-Heating Process and Thermal Runaway}

The temporary storage of dried sewage material caused problems at several Swiss cement plants, however, because of frequent spontaneous temperature increases within the stored granules. This self-heating is sometimes followed by a thermal runaway and a consecutive fire if the silo is not emptied rapidly enough. In addition the feed of the granules to the furnace is prevented due to the formation of sintered material which obstructs pipes and valves (Fig. 1). Such incidents seriously damage all efforts aimed at highlighting the value of dried sewage granules as a $\mathrm{CO}_{2}$-neutral alternative fuel.

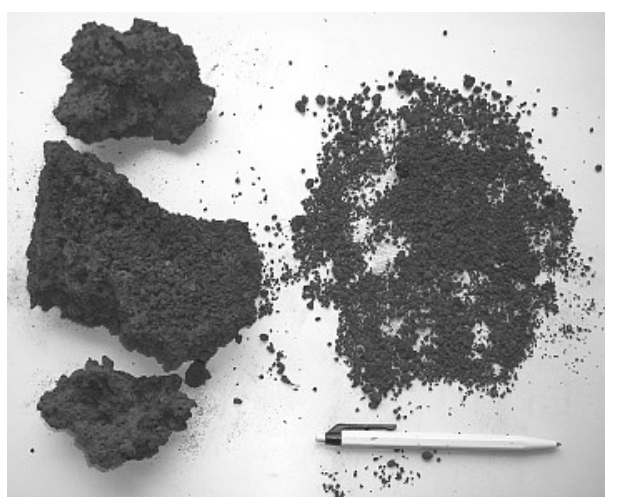

Fig. 1. Sintered blocks (left) after a thermal event during storage of dried sewage granules (right)

It was observed that these thermal events and the consecutive fires happened more frequently after the delivery of sewage granules from the Bern STP. However, sewage sludge produced at the Bern STP has the same composition as the sewage waste of other STPs in Switzerland, except for its fairly high iron content $\left(\mathrm{Fe}_{\text {tot }}\right.$ $7-12 \%$ DS) resulting from the addition of iron chlorosulfate $\left(\mathrm{FeClSO}_{4}\right)$ to precipitate phosphates and to increase the weight of the bio-waste for faster sedimentation.

\section{Research Project}

The occasional smoldering fires in the storage silos considerably disrupt working schedules and processes at the cement production plants and hence the timely elimination of the dried sludge from the sewage treatment plants. Therefore the different stakeholders, the Swiss Federal Office for the Environment (FOEN), the Association of the Swiss Cement Industry (CEMSUISSE) and the Bern STP (ARA Bern AG) decided to mandate us with a research project on the thermal runaway of dried sewage sludge in storage tanks. This initial project was later expanded to the College of Engineering and Architecture of Fribourg through a larger project financed by the Innovation Promotion Agency (CTI).

With the objective of understanding thermal runaway in the stored sewage granules from its intrinsic origins to the resulting fire, the project aimed also at providing technical measures for fire prevention. The project consisted therefore in an experimental part including large-scale (multi-tonne) storage experiments and in a more fundamental research part including a thorough material characterization.

Our first assumption was that some of the organic material of the sludge spontaneously undergoes auto-oxidation releasing enough energy to keep the process going, or eventually to accumulate enough heat to start the combustion of the remaining organic material. The addition of antioxidants was expected to retard this decomposition. This assumption was tested in large-scale storage experiments using freshly produced sewage granules with and without antioxidant treatment. At the same time the impact of pneumatic transfer utilized in unloading the granules from the transporting truck to the silo was examined.

As this first assumption could not be validated, a systematic investigation of the physical properties and the thermal behavior of the material was initiated along the following working hypotheses:

i) low-temperature oxidation of the organic material under specific conditions;

ii) surface oxidation due to the pneumatic transfer from the transporting truck to the silo;

iii) an external event as ignition source of a weakly reactive 'granules - air - humidity' system;

iv) biological activity of residual microorganisms;

v) auto-oxidation of the organic material catalyzed by transition metal species (e.g. $\left.\mathrm{Fe}^{3+}\right)$;

vi) pyrophoric activity caused by iron sulfide;

vii) exothermic hydration of dry sewage granules by moisture.

\section{Experimental Results}

Storage experiments with three selected antioxidants (sodium hypophosphite $\left(\mathrm{Na}_{2} \mathrm{HPO}_{2}\right), \mathrm{Ciba}^{\circledR}$ Prostab $^{\circledR} 5198$ and Ciba ${ }^{\circledR}$ HTMP) were performed in a model silo of $18 \mathrm{~m}^{3}$ (Fig. 2), a small model compared to the typical $175 \mathrm{~m}^{3}$ storage silos used in industry, at a scale of about twelve tonnes of freshly dried sewage granules. The antioxidants were selected according to three criteria: costs and availability (sewage is not a material of high added value like polymers), water solubility and mode of action. The antioxidants were added by injecting them as aqueous solutions in the

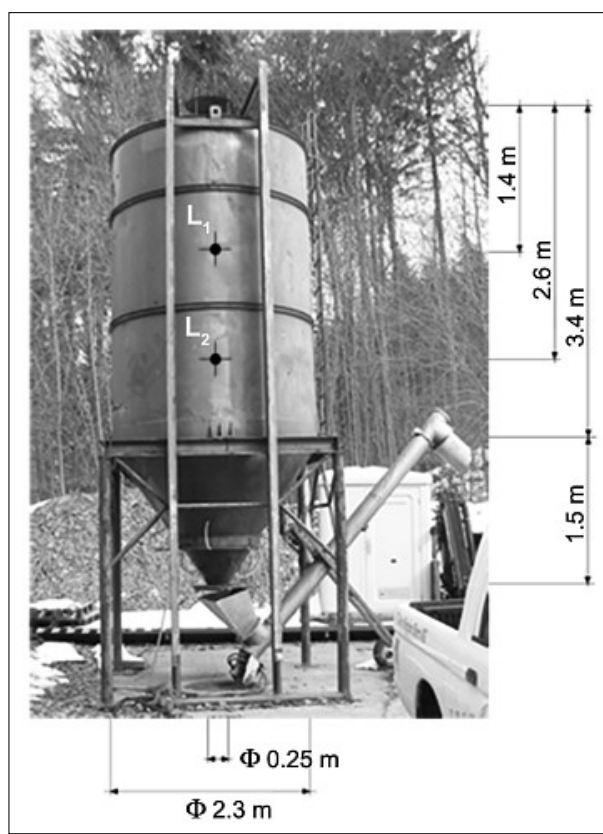

Fig. 2. Experimental storage silo $\left(18 \mathrm{~m}^{3}\right)$ allowing several manual temperature measurements $\left(T_{1}\right.$, $\mathrm{T}_{2}, \mathrm{~T}_{3}$ and $\left.\mathrm{T}_{4}\right)$ at three different depths $(0.60,0.85$ and $1.10 \mathrm{~m}$ ), continuous temperature logging in the centre of the silo ( $L_{1}$ and $L_{2}$, locations shown), the monitoring of the humidity and the carbon monoxide concentration $(\mathrm{M})$ and the manual sampling of stored granules $\left(S_{1}\right.$ and $\left.S_{2}\right)$

dewatered sludge before the final drying stage. The resulting antioxidant loading amounted to $\sim 0.1 \%$.

The fluidized bed dryer plant at the Bern STP operates at $85^{\circ} \mathrm{C}$ in a combustion gas atmosphere (oxygen content $\sim 4-6 \%$ ). After passing under the same protective atmosphere through a cooler the dry material is accumulated in a temporary storage silo, from which the granules are directly discharged to a transport truck without air contact. The pneumatic transfer of the dried sewage granules from the truck to the experimental silo uses hot compressed air $\left(120{ }^{\circ} \mathrm{C}\right)$ as in the regular delivery at the cement industry. In some experiments this compressed air was chilled to $\sim 15^{\circ} \mathrm{C}$ prior to the contact with the material. During loading at the top of the silo a ventilator vented the resulting dust.

Out of the six experiments performed only one showed no thermal runaway (Table). In all cases the initial temperature of the material $\left(\sim 40{ }^{\circ} \mathrm{C}\right)$ increased within $2-7 \mathrm{~h}$ to $80-100{ }^{\circ} \mathrm{C}$, as indicated by the two temperature $\log$ gers $\mathrm{L}_{1}$ and $\mathrm{L}_{2}$ fitted to the experimental silo (Fig. 3). After staying at this temperature for about three days a sudden further temperature increase was noted (c.f. Fig. 3), exceeding in some cases $600{ }^{\circ} \mathrm{C}$. By adding antioxidants this steep temperature increase was retarded by about $24 \mathrm{~h}$ in the case of $\mathrm{Na}_{2} \mathrm{HPO}_{2}$ and by $12 \mathrm{~h}$ in the case of Prostab ${ }^{\circledR}$ (Table) compared to a blank experiment without antioxidant. 
Table. Onset and maximum temperature increase for the thermal events (self-heating and thermal runaway) spontaneously occurring during the storage of dried sewage granules (Bern STP) in a largescale experimental silo

\begin{tabular}{|c|c|c|c|c|c|c|c|}
\hline \multirow[t]{2}{*}{ Exp. } & \multirow{2}{*}{$\begin{array}{l}\text { Pneumatic } \\
\text { loading }\end{array}$} & \multirow{2}{*}{$\begin{array}{l}\text { Antioxidant } \\
\text { treatment }\end{array}$} & \multirow[t]{2}{*}{ Pos. } & \multicolumn{2}{|c|}{ Self-heating ${ }^{a}$} & \multicolumn{2}{|c|}{ Thermal runaway } \\
\hline & & & & $T_{\text {onset }}\left(t_{\text {onset }}\right)$ & $\mathrm{T}_{\max }\left(\mathrm{t}_{\max }\right)$ & $T_{\text {onset }}\left(t_{\text {onset }}\right)$ & $\mathrm{T}_{\max }\left(\mathrm{t}_{\max }\right)$ \\
\hline \multirow{2}{*}{1} & \multirow{2}{*}{ Hot air } & \multirow{2}{*}{-} & $\mathrm{L}_{1}$ & $51.1(7.4 \mathrm{~h})$ & $95.8(10.9$ h) & 88.9 (72.2 h) & $250.7(97.7$ h) \\
\hline & & & $\mathrm{L}_{2}$ & 46.0 (4.2 h) & 83.4 (5.9 h) & $32.4(111.9 \mathrm{~h})$ & $762.0(125.8 \mathrm{~h})$ \\
\hline \multirow{2}{*}{2} & \multirow{2}{*}{ Hot air } & \multirow{2}{*}{$\mathrm{Na}_{2} \mathrm{HPO}_{2}$} & $\mathrm{~L}_{1}$ & $48.8(7.8$ h) & $96.2(9.7$ h) & $84.4(81.3 \mathrm{~h})$ & $312.4(84.7$ h) \\
\hline & & & $\mathrm{L}_{2}$ & $49.0(2.2 \mathrm{~h})$ & $86.5(2.9$ h) & $42.0(136.6 \mathrm{~h})$ & 495.5 (142.8 h) \\
\hline \multirow{2}{*}{3} & \multirow{2}{*}{ Hot air } & \multirow{2}{*}{ Prostab $^{\circledR}$} & $\mathrm{L}_{1}$ & $47.2(15.4 \mathrm{~h})$ & $93.8(17.4 \mathrm{~h})$ & $93.8(50.9$ h) & $189.2(119.3 \mathrm{~h})$ \\
\hline & & & $\mathrm{L}_{2}$ & $52.0(6.5 \mathrm{~h})$ & 86.5 (8.5 h) & $61.5(123.7 \mathrm{~h})$ & $648.5(138.5$ h) \\
\hline \multirow{2}{*}{$4^{b}$} & \multirow{2}{*}{ Cold air } & \multirow{2}{*}{-} & $\mathrm{L}_{1}$ & $46.0(3.9 h)$ & $96.2(10.7$ h) & $-{ }^{c}$ & - \\
\hline & & & $\mathrm{L}_{2}$ & $44.1(1.8 \mathrm{~h})$ & $61.8(5.9 h)$ & - & - \\
\hline \multirow{2}{*}{5} & \multirow{2}{*}{ Cold air } & \multirow{2}{*}{-} & $\mathrm{L}_{1}$ & $43.0(17.2 \mathrm{~h})$ & $96.2(21.2$ h) & - & - \\
\hline & & & $\mathrm{L}_{2}$ & 56.5 (5.6 h) & $86.5(10.0 \mathrm{~h})$ & 76.5 (88.9 h) & 678.0 (99.9 h) \\
\hline \multirow{2}{*}{$6^{d}$} & \multirow{2}{*}{ Cold air } & \multirow{2}{*}{ HTMP } & $\mathrm{L}_{1}$ & $46.0(22.1 \mathrm{~h})$ & $96.2(24.2$ h) & 43.0 (177.2 h) & $333.0(187.3$ h) \\
\hline & & & $\mathrm{L}_{2}$ & $42.0(22.2$ h) & $91.0(22.6$ h) & $52.0(171.1 \mathrm{~h})$ & 239.0 (181.2 h) \\
\hline
\end{tabular}

a) $\mathrm{T}_{\text {onset }}$ for the initial temperature $\left[{ }^{\circ} \mathrm{C}\right]$ at the beginning of the thermal event and $\mathrm{T}_{\max }$ for the maximal peak temperature $\left[{ }^{\circ} \mathrm{C}\right]$, occurring respectively at time $t_{\text {onset }}[\mathrm{h}]$ and $\mathrm{t}_{\max }[\mathrm{h}]$

b) The loading pipes were closed during the whole storage experiment preventing the venting on the top surface of the stored granules

c) No thermal runaway occurred after the self-heating process

d) The ventilation at the top of the stored granules was started $0.7 \mathrm{~d}$ after the start of the storage experiment due to a fan dysfunction
In a second series of experiments (entries 4-6) chilled compressed air was used for the pneumatic transfer. Comparison of experiment 1 and 5 show no significant difference, however, since in both cases a thermal runaway after three days occurred, with the only difference that this time the hot zone appeared in the centre of the material (data $\operatorname{logger} \mathrm{L}_{2}$ ) and not near the surface $\left(\operatorname{logger} \mathrm{L}_{1}\right)$. The other blank experiment under these conditions surprisingly showed no thermal runaway, despite a first thermal

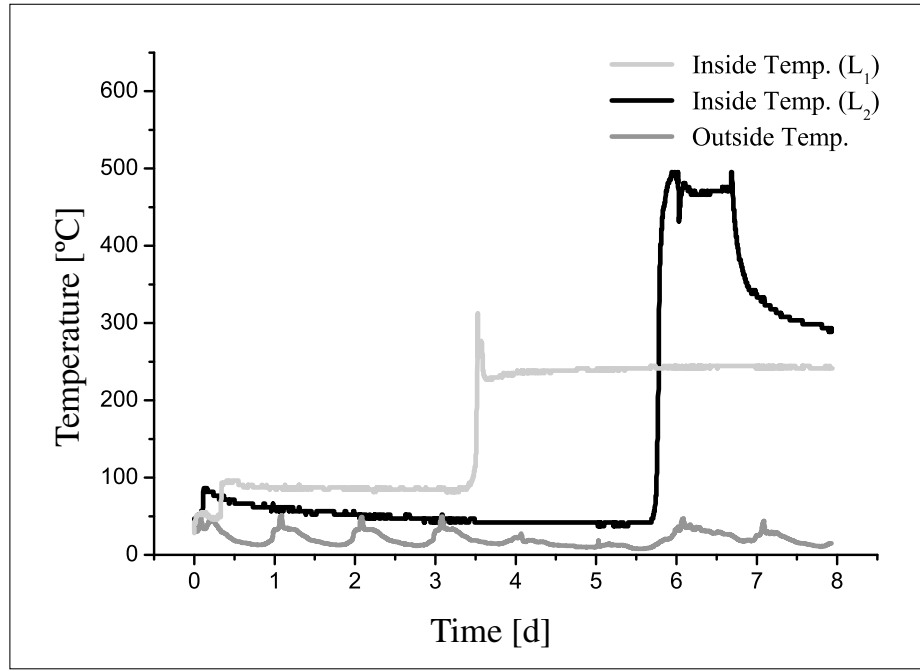

Fig. 3. Self-heating and thermal runaway occurring during the storage of the dried sewage granules treated with sodium hypophosphite $\left(\mathrm{Na}_{2} \mathrm{HPO}_{2}\right)$, loaded with hot compressed air event as in all other experiments. It has to be noted that in this experiment the two loading pipes were closed after charging the silo, a measure that somehow reduced the fresh air intake during storage. This experiment was stopped after eight days monitoring because the measured temperature monotonously decreased to the initial value, but as the last experiment (entry 6) shows, a runaway could still have happened at a later time. Experiment 6, a run in presence of the antioxidant HTMP is remarkable for several reasons: firstly, due to a malfunction of the ventilator at the top of the silo, venting was interrupted for the first $18 \mathrm{~h}$. No temperature increase was noted during this time. But $4 \mathrm{~h}$ after starting the ventilator the usual temperature rise above $90{ }^{\circ} \mathrm{C}$ was noted. Secondly, despite a monotonous temperature decrease to 43 and $52{ }^{\circ} \mathrm{C}$ for the two sensor positions $\mathrm{L}_{1}$ and $\mathrm{L}_{2}$, respectively, a sudden rise of the temperature was noted $6 \mathrm{~d}$ later. Shutting off the oxygen supply obviously does not prevent the thermal events, but merely delays them.

Clearly the antioxidant treatment could not suppress a thermal runaway. Furthermore the antioxidants do not appear to influence the first temperature increase, which regularly occurs within hours after charging the storage silo. Air seems to be an important factor for the first temperature increase, as shown in experiment 6 where the defect ventilator delayed the first thermal event for the time that it is was not running. We therefore decided to examine closer this first thermal event, since we argued that it triggers the subsequent self-heating of the material, which ultimately results in a fire.

The first working hypothesis of a lowtemperature oxidation of the organic material has to be rejected because no change of the organic fraction could be detected by solid-state ${ }^{13} \mathrm{C}$ MAS-NMR before and after storage with heating up to $80^{\circ} \mathrm{C}$. Likewise the $\mathrm{CHN}$ analysis values remain invariant during storage at room temperature, at 50 ${ }^{\circ} \mathrm{C}$ or at $80{ }^{\circ} \mathrm{C}$. Moreover TG-MS analyses showed only the loss of water when heated to $100{ }^{\circ} \mathrm{C}$, which is not surprising since the sewage granules still contain $\sim 8 \%$ w/w water. However, DSC measurements performed in air show a very small exothermic peak between $50{ }^{\circ} \mathrm{C}$ and $150{ }^{\circ} \mathrm{C}$ (Fig. 4). Repeating the experiment under nitrogen flow, the expected endothermic peak corresponding to the water evaporation is now clearly visible, which indicates that the water evaporation is balanced by an exothermic process taking place in the same temperature range. As the noted heating effect shown in the difference of the two DSC runs (Fig. 4), executed on very small quantities (a few milligrams), cannot be explained by a heat accumulation phenomena as in large-scale storage, this exothermicity hints to a self-heating process. In addition 


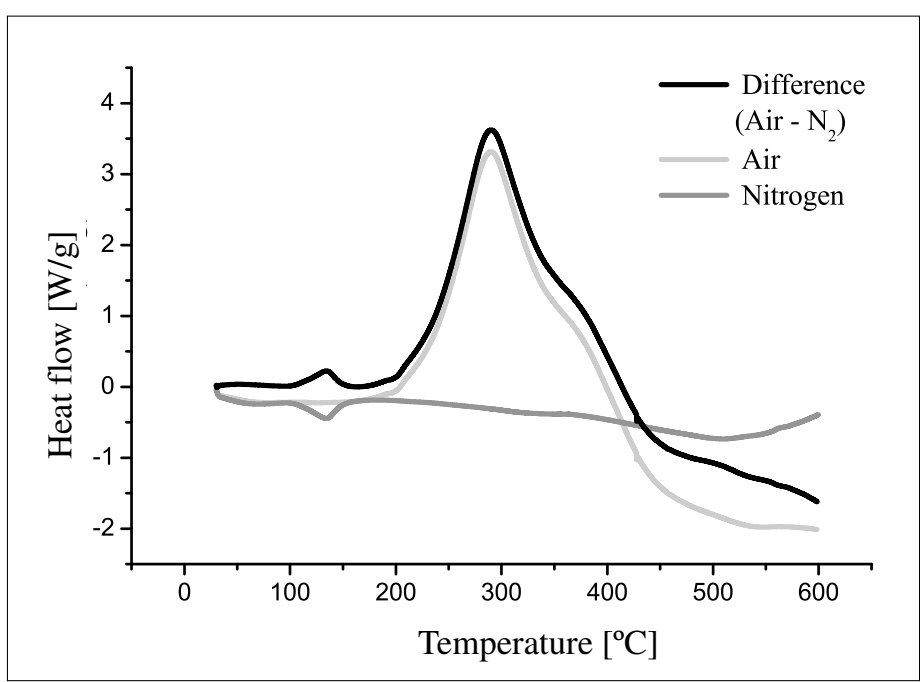

Fig. 4. DSC analyses of dried sewage granules performed at $5 \mathrm{~K} / \mathrm{min}$, from 30 to $600^{\circ} \mathrm{C}$, under air and nitrogen flow $(100 \mathrm{ml} / \mathrm{min})$

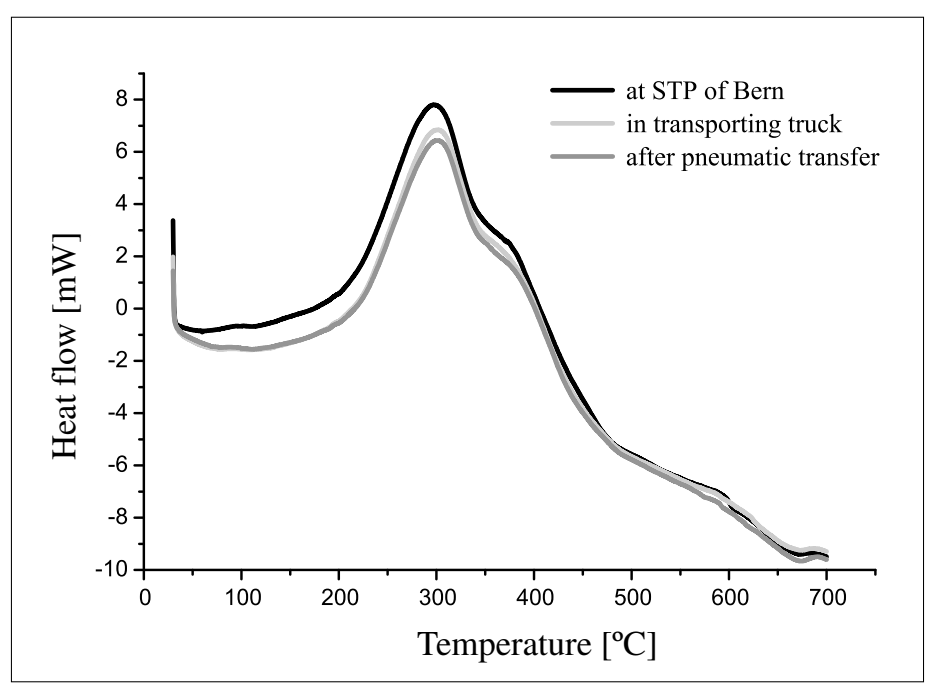

Fig. 6. DSC analyses of dried sewage granules taken a) at the dryer plant of the Bern STP, b) in the transporting truck after loading, and c) in the pipe after the pneumatic transfer from the truck to the storage silo at the cement industry. Measurements performed under air-flow at $3 \mathrm{~K} / \mathrm{min}$, from 30 to $700{ }^{\circ} \mathrm{C}$.

this thermal event fades with progressive age of the sample: once this first event is over spontaneous self-heating is no longer observed.

Combustion analyses show that this exothermic process is oxygen demanding, because the oxygen concentration already decreases at storage temperatures exceeding $30{ }^{\circ} \mathrm{C}$. This oxygen consumption was confirmed by small-scale (6-8 1) storage experiments in insulating Dewar recipients: blowing air through the material clearly results in an accelerated self-heating on a much shorter time scale compared to storage experiments without additional air (Fig. 5). This experiment closely resembles reality, because each addition of a new batch of granules in the industrial storage silo supplies the already stored material with fresh air, thereby maintaining the oxidative process. But despite its dependence on oxy-

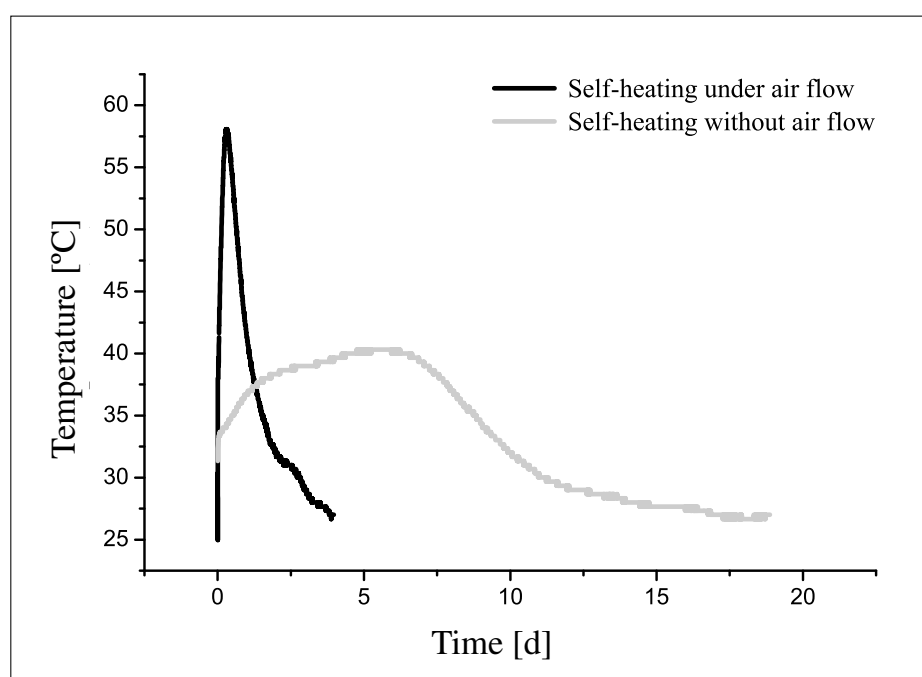

Fig. 5. Spontaneous temperature increase measured during isothermal storage of dried sewage granules in an insulated container (6.7 I Dewar) kept at RT thermicity at $100{ }^{\circ} \mathrm{C}$ ) observed for samples fresh out of the dryer plant (Fig. 6). As already shown in the large-scale storage experiments, no significant difference was noted between experiments with normal (hot air) pneumatic transfer and the ones using chilled air. Although the process is oxygen-dependent, it appears that self-heating requires, more importantly, the thermal insulating properties of settled material that prevents any heat dissipation. Even if the air of the pneumatic transfer could allow accelerated surface oxidation, the produced heat would be removed by the air-flow.

Occasional ignition events, such as electrostatic discharges in the storage silo or during pneumatic transfer, fluctuating composition of the granules, or spurious amounts of highly reactive material were invoked in a third hypothesis. However, experiments showed that the residual conductivity of dried sewage sludge is high enough to prevent static charge accumulation. The composition of the material fluctuates but within surprisingly narrow limits, as shown in numerous analyses. Furthermore there is no correlation between the composition of the material and the noted thermal events. Although in all large-scale storage experiments the fire finally started in specific locations, the events could not be explained by predetermined hot spots but rather by randomly cooperating parameters, which cross a critical threshold at a location given by chance.

Biological activity is a frequently cited hypothesis as a possible ignition source of organic material. Residual microorganism activity in sewage granules was therefore studied. Although the presence of bacterial spores within the material was confirmed, these microorganisms, mainly E. Coli, are in a dormant state because dried sewage granules do not provide a sufficiently nutritive media for biological growth. Therefore 
the self-heating observed in our case cannot be attributed to the biological activity of the residual microorganisms. In addition a biological process would require a much longer induction period (days to weeks) and a much larger moisture content to lead to self-heating, whereas the observed spontaneous temperature increase occurs within a few hours only, and this at a very low moisture content, where in addition part of it is even bound as crystal water. Moreover E. Coli is a typical mesophile with a maximum growth temperature of $48{ }^{\circ} \mathrm{C}$, preventing any further biological activity at higher temperatures.

Our initial hypothesis, the auto-oxidation of the organic material catalyzed by some transition metal species, especially iron, was investigated in detail, because iron is present in large amounts in the final sewage waste. During the waste water treatment, Fe(III) is added as iron chloride sulfate to raw sewage flows arriving at the Bern STP for phosphate precipitation. Later in the sludge treatment route, the iron is reduced to $\mathrm{Fe}(\mathrm{II})$ under the anaerobic conditions of the digesters. This is confirmed by the iron speciation of liquid sludge samples (Fig. 7), in which nearly $80 \%$ of the total iron content is Fe(II). After centrifugation, this $\mathrm{Fe}(\mathrm{II}) / \mathrm{Fe}$ (III) ratio stays constant for the dewatered sludge samples, whereas after the drying process the $\mathrm{Fe}(\mathrm{II}) /$ $\mathrm{Fe}$ (III) ratio drops to $50 \%$ (Fig. 7). This oxidation occurs under the dryer working conditions at around $85{ }^{\circ} \mathrm{C}$ and under a low oxygen atmosphere ( $<4 \%$ vol.). During the storage of the dried sewage granules, iron oxidation continues due to the presence of residual oxygen and air leaking in.

In the dried sewage granules, a large fraction of the ferrous iron is present as crystalline vivianite, $\mathrm{Fe}_{3}\left(\mathrm{PO}_{4}\right)_{2} \cdot 8 \mathrm{H}_{2} \mathrm{O}$, which corresponds to at least $20 \%$ of the total iron present in the dried material as shown by powder XRD analysis, quantified by the Rietveld method. A large fraction of the remaining iron is microcrystalline or amorphous iron phosphate, not detected by powder XRD analysis, but deduced from the known amount of phosphate present. The remaining iron salts are amorphous compounds of unknown composition. As shown by high temperature powder XRD the crystalline vivianite is stable in air up to $75{ }^{\circ} \mathrm{C}$, but starts to decompose at higher temperatures due to the oxidation of $\mathrm{Fe}$ (II) and by releasing the crystalline water molecules. Vivianite decomposition is hence a process that could explain in part a sustained temperature in the $90-110^{\circ} \mathrm{C}$ range, but not the initial temperature raise starting from the initial level of $30-40{ }^{\circ} \mathrm{C}$ to the elevated temperature of $80-90{ }^{\circ} \mathrm{C}$. As this first temperature surge is not affected by added antioxidants, one can safely conclude that auto-oxidation of the organic material is not responsible for it.

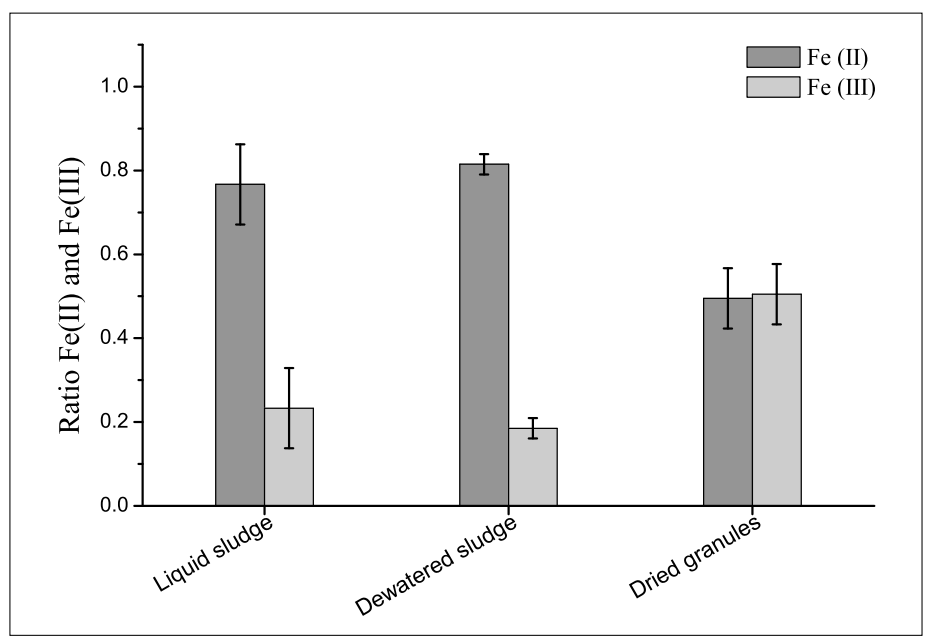

Fig. 7. Fe(II)/Fe(III) ratio in fresh samples of liquid sludge, dewatered sludge and dried sewage granules determined by ILC

The sewage of the Bern STP is rich in sulfate due to the added $\mathrm{FeClSO}_{4}$, since only a small part of the sulfate leaves the purification process in the form of soluble salts in the cleared run-off water. Sulfate-reducing bacteria like desulfobulbus are known to occur in sewage, and the presence of $\mathrm{Fe}$ (III), which is concurrently reduced to $\mathrm{Fe}$ (II), is beneficial for their action, since it removes (inhibitory) $\mathrm{H}_{2} \mathrm{~S}$ formed in the reaction as insoluble FeS. Iron sulfide is known to be oxidized by oxygen to yield Fe(III) and elemental sulfur. Although elemental analysis determines for dried sewage granules a sulfur content of $\sim 1 \%$, sulfide could not be detected by a classical analysis (addition of conc. $\mathrm{HCl}$ while bubbling the headspace gas through a $\mathrm{Pb}(\mathrm{OAc})_{2}$, solution). Since a test for sulfide likewise failed on dried sewage granules spiked with $\mathrm{FeS}$, but worked perfectly on material spiked with $\mathrm{Na}_{2} \mathrm{~S}$, the presence of iron sulfide cannot be excluded. It has to be noted, however, that sulfide is oxidized to sulfur in the presence of a system containing $\mathrm{Fe}(\mathrm{III})$.

The presence of iron sulfide was therefore indirectly proven by serendipity: at the end of several storage experiments the formation of minute quantities of tiny crystals was noted on the surface of the granules.

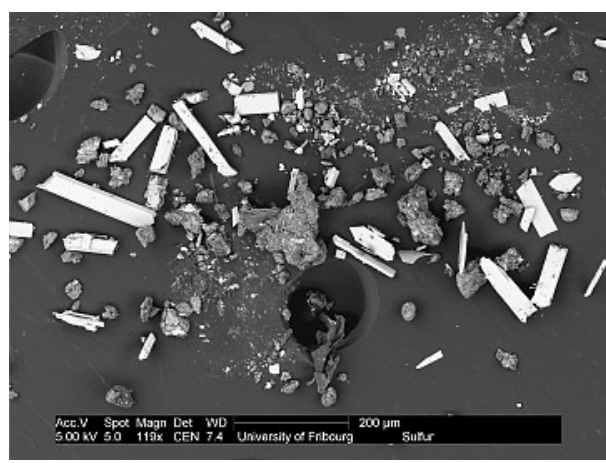

Fig. 8. SEM and EDS microanalysis of the sulfur crystals formed during the storage of dried sewage granules
Storage experiments with added moisture yielded even larger crystals (Fig. 8), which finally allowed them to be identified by single crystal X-ray analysis as monoclinic $\gamma$-sulfur. This high-temperature allotrope is known to form under lower pressure in a temperature range of $100-115^{\circ} \mathrm{C}$ only, a finding which hints in our case to formation under highly exothermal conditions.

The last hypothesis involves hydration as an exothermic process. It was noted that large granules $(>3 \mathrm{~mm})$ typically showed a considerably higher moisture content ( $82 \%$ DS) compared to smaller granules ( $<3 \mathrm{~mm},>92 \% \mathrm{DS})$. After storage this difference vanished. Addition of small quantities of water $(0.6 \% \mathrm{w} / \mathrm{w})$ provoked exothermal events, even after extended storage (Fig. 9). Although one could argue that evaporation and re-absorption of water would be energetically neutral, it could nevertheless present a mechanism for propagating heat through the material, which otherwise behaves as a very good thermal insulator with a measured thermal conductivity of 0.33 $\mathrm{Wm}^{-1} \mathrm{~K}^{-1}$ and a thermal diffusivity of 0.44 $\mathrm{mm}^{2} \mathrm{~s}^{-1}$; values comparable to wood chips and glass, respectively. In addition, the distinctively enhanced formation of sulfur crystals in the presence of added moisture hints to an accelerated iron sulfide oxidation in the presence of traces of water.

\section{Conclusion}

Our observations and experiments clearly show that thermal runaway in stored dry sewage granules cannot be attributed to a single process, but is rather the consequence of a series of sequential events, accentuated by the very low thermal conductivity of the material, which favors the accumulation of heat. At first, sulfide is oxidized to sulfur and the remaining $\mathrm{Fe}$ (II) converted to $\mathrm{Fe}$ (III). The exothermicity of these events decom- 


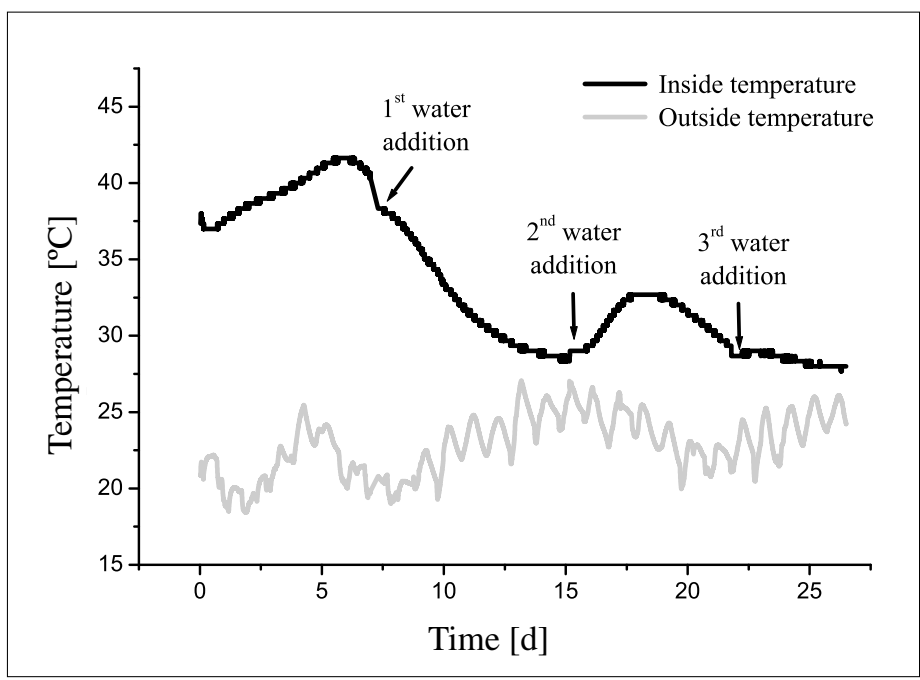

Fig. 9. Spontaneous temperature increase measured during the storage of dried sewage granules $(9.4 \mathrm{~kg})$ in an insulated container (14.2 I Dewar) with water additions (60 $\mathrm{ml}$ each)

poses the crystalline vivianite, releasing thereby its crystal water. Exothermal reabsorption of this water by neighboring material adds to the heat already produced and accelerates the $\mathrm{FeS}$ oxidation. If the air present in the silo cannot remove the heat by convection, heat accumulates further until auto-oxidation of the organic material sets in at $\sim 120{ }^{\circ} \mathrm{C}$.

Although all the exothermic processes discussed are oxygen-dependent, the use of totally inert conditions for transport, handling and storage of the material is not a practical solution in view of the volumes and procedures involved. In addition, as one of the large-scale storage experiments shows, thermal runaway is prevented if the first thermal event relaxes slowly as achieved by controlling the amount of oxygen available. Under these conditions heat production from oxidation of the inorganic material never exceeds heat dissipation and hence prevents heat accumulation, which would trigger the auto-oxidation of the organic material as a secondary event.
Preventive measures would therefore include either excessive venting of small enough batches of the material, or alternatively reducing the contact with air as much as possible with concomitant rapid consumption of the reactive material.

Replacing the commodity chemical $\mathrm{FeClSO}_{4}$ by the more expensive $\mathrm{FeCl}_{3}$ or even aluminum salts would present another possible solution of the problem, however rejected by the STP because of other problems associated with these chemicals: aluminum compounds would not bind the present hydrogen sulfide in the bioreactors, and $\mathrm{FeCl}_{3}$ is feared because of its corrosive behavior with respect to the stainless steel installations.

As a third and probably most effective preventive measure the oxygen content in the dryer atmosphere could be raised from the present $\sim 4 \%$ to a value near $10 \%$ to oxidize the inorganic material at a stage where heat accumulation is excluded.

Finally the installation of oxygen sensors in the storage silos could help in early detection of thermal events, since any slow- ly accelerating chemical process would start to consume the available oxygen; its concentration would start to drop. Experimental trials would allow a critical level to be defined at which emptying of the storage silo would be indicated. This technical measure is already applied at one cement plant (Vigier, CH-Péry) presenting obviously a good solution, as no smoldering fire has occurred since.

Not recommended are heat exchanger installations in the storage silo: the low thermal conductivity of the sewage granules would require an impractical dense packing of the cooling tubes.

\section{Acknowledgements}

This project was funded by the Swiss Federal Office for the Environment (FOEN), the Association of the Swiss Cement Industry (CEMSUISSE), the Sewage Treatment Plant of Bern (ARA Bern AG) and the Innovation Promotion Agency (CTI).

Received: November 24, 2007

[1] J. Werther, T. Ogada, Progr. Energy Combust. Sci. 1999, 25, 55.

[2] I. S. Turovskiy, 'Wastewater sludge processing', Wiley-Interscience, 2006.

[3] Swiss Federal Office for Agriculture, Agricultural Report 2001, 2001.

[4] V. Sandroni, C. M. M. Smith, Anal. Chim. Acta 2002, 468, 335.

[5] D. Schowanek, R. Carr, H. David, P. Douben, J. Hall, H. Kirchmann, L. Patria, P. Sequi, S. Smith, S. Webb, Regul. Toxicol. Pharmacol. 2004, 40, 227.

[6] O. Jones, N. Voulvoulis, J. Lester, Environ. Pol. 2007, 145, 738.

[7] O. A. H. Jones, N. Voulvoulis, J. N. Lester, Wat. Res. 2002, 36, 5013.

[8] Swiss Federal Office for Environment, Utilisation des matières premières et élimination des déchets dans une optique durable, Bases pour l'élaboration de la future politique fédérale, 2006.

[9] Swiss Federal Office for Environment, Élimination des boues d'épuration en Suisse, Documentes Environnement N¹81 (Déchets), 2004. 